\title{
Using Neurofeedback to Improve ADHD Symptoms in School-Aged Children
}

\author{
Connie J. McReynolds ${ }^{1 *}$, Lelah S. Villalpando ${ }^{2}$, and Cynthia E. Britt ${ }^{3}$ \\ ${ }^{1}$ Institute of Research, Assessment \& Professional Development, California State University, San Bernardino, San \\ Bernardino, California, USA \\ ${ }^{2}$ Loma Linda University, Loma Linda, California, USA \\ ${ }^{3}$ Bear Valley Unified School District, Big Bear, California, USA
}

\begin{abstract}
The diagnosis and treatment of the behaviors associated with attention-deficit/hyperactivity disorder (ADHD) predominantly involves pharmacological interventions. Many children experience significant negative side effects (e.g., appetite suppression, insomnia, headaches, stomachaches, irritability, and impaired height) from the initial and continued use of stimulant medication. Consequently, many parents are motivated to consider alternative treatments for ADHD such as neurofeedback. This paper presents an archival review of the improvements in auditory and visual attention and response control after 40 sessions of artifact-corrected neurofeedback for 51 children ages 6 to 17 with ADHD. Initially, the majority of these clients were identified as having severe to extreme auditory and visual attention impairments. The IVA-2 CPT was administered prior to treatment and after 20 and 40 treatment sessions were completed. After 20 sessions of neurofeedback significant improvements of both auditory and visual attention and response control were found with small to large size effects. The clients continued to improve after an additional 20 sessions, with medium to large size effects after 40 sessions. At completion of treatment the mean of eight of the nine attention and response control scores fell within the "normal" range.
\end{abstract}

Keywords: attention-deficit/hyperactivity disorder (ADHD); auditory processing; visual processing; neurofeedback; Integrated Visual and Auditory (IVA2) Continuous Performance Test; nonpharmacological

Citation: McReynolds, C. J., Villalpando, L. S., \& Britt, C. E. (2018). Using neurofeedback to improve ADHD symptoms in school-aged children. NeuroRegulation, 5(4), 109-128. http://dx.doi.org/10.15540/nr.5.4.109

*Address correspondence to: Connie J. McReynolds, PhD; Director, Institute of Research, Assessment \& Professional Development; Department of Special Education, Rehabilitation \& Counseling, College of Education; California State University, San Bernardino, 5500 University Parkway, San Bernardino, CA 92407, USA. Email: cmcreyno@csusb.edu

Copyright: @ 2018. McReynolds et al. This is an Open Access article distributed under the terms of the Creative Commons Attribution License (CC-BY).
Edited by:

Rex L. Cannon, PhD, Knoxville Neurofeedback Group, Knoxville, Tennessee, USA

Reviewed by:

Randall Lyle, PhD, Mount Mercy University, Cedar Rapids, lowa, USA

Nancy L. Wigton, PhD, Grand Canyon University, Phoenix, Arizona, USA

\section{Introduction}

According to Visser, Zablotsky, Holbrook, Danielson, and Bitsko (2015), about $11 \%$ of children, or some 6.4 million school-aged children (i.e., > 1 in 10), in the United States have been diagnosed with AttentionDeficit/Hyperactivity Disorder (ADHD). In fact, the percentage of children diagnosed with this disorder increased $42 \%$ between the years 2003 to 2012 (Visser et al., 2015). Child-learning experts believe that many more teens and children are being diagnosed with an attention-deficit disorder than is merited (e.g., Grohol, 2013). Contributing factors to the increased diagnosis of ADHD will be discussed, coupled with a discussion on using neurofeedback as an alternative treatment method for ADHD.

The purpose of this archival study was to evaluate the clinical effectiveness of neurofeedback treatment for children who presented with a variety of attentional and behavioral symptoms including anxiety, panic attacks, learning, concentration difficulties, sleep disorders, depression, and memory concerns. It was hypothesized that the Integrated Visual and Auditory Continuous Performance Test - Version 2 (IVA-2 CPT) global measures of visual and auditory attention 
processing would show a significant improvement after both 20 and 40 sessions of treatment with the greatest degree of improvement expected after 40 treatment sessions.

\section{Traditional Diagnostic Processes for ADHD}

Psychiatrists, physicians, psychologists, social workers, and school counselors, along with community, parent, and children's support groups all exist to help children better manage their dysregulated behaviors. In addition, numerous types of pharmacological and behavioral interventions are commonly utilized toward correcting the undesirable behaviors. Yet, with all this support, children still experience negative outcomes from their inappropriate behaviors. Most importantly, academic improvement due to any of these interventions alone, or in combination, has not shown long-term results in that children continue to struggle with low self-esteem and perform poorly academically, some to the point of dropping out of school (Lee, Lahey, Owens, \& Hinshaw, 2008; Owens, Hinshaw, Lee, \& Lahey, 2009). In all, because they are not behaving appropriately, children with ADHD symptoms continue to demonstrate difficulty with developing appropriate family, school, and social interactions.

The two primary methods to diagnose ADHD are specified by either the American Psychiatric Association (APA) Diagnostic and Statistical Manual Fifth Edition (DSM-5; APA, 2013), or the International Statistical Classification of Diseases and Related Health Problems, 10th Revision, in the form of the ICD-10, a global coding system developed by the World Health Organization (WHO) for classifying diseases and clinical procedures. Other factors that may increase ADHD diagnoses include medical conditions that mimic ADHD, along with the influence of both national- and state-based educational policies. Such policies support the eligibility of ADHD under the criteria of Other Health Impaired for special education services within the school systems. A brief review of the DSM-5 diagnostic criteria for childhood ADHD identifies three primary diagnostic classifications, which include the specifiers of inattention, hyperactivity/impulsivity, or both (see Table 1).

The criteria for the diagnosis of ADHD, Predominately Inattentive Presentation requires the child must be 17 years of age or younger and exhibit six or more of the symptoms (see Table 1.A.) for at least 6 months. In addition, these symptoms must be inconsistent with the child's developmental level, have a negative effect on the child's social and academic activities, and occur often. The criteria for the diagnosis of ADHD, Predominately Hyperactive-Impulsive Presentation indicates that six or more of the listed symptoms (see Table 1.B.) must be present for at least 6 months, must be inconsistent with the child's developmental level, must have a negative effect on the child's social and academic activities, and must occur often. The diagnosis of ADHD Combined Presentation (see Table 1.C.) is given when the child meets both sets of criteria.

\section{Table 1}

DSM-5 General Diagnostic Criteria.

\section{A. Inattention}

1. Fails to pay close attention to details

2. Has trouble sustaining attention

3. Does not seem to listen when spoken to directly

4. Fails to follow through on instructions and fails to finish schoolwork or chores

5. Has trouble getting organized

6. Avoids or dislikes doing things that require sustained focus/thinking

7. Loses things frequently

8. Easily distracted by other things

9. Forgets things

\section{B. Hyperactivity/Impulsivity}

1. Fidgets with hands/feet or squirms in chair

2. Frequently leaves chair when seating is expected

3. Runs or climbs excessively

4. Trouble playing/engaging in activities quietly

5. Acts "on the go" and as if "driven by a motor"

6. Talks excessively

7. Often blurts out answers before questions are completed

8. Trouble waiting or taking turns

9. Interrupts or intrudes on what others are doing

C. Inattentive and Hyperactive/Impulsive (Combined Presentation)

Both criterion of inattention and hyperactivityimpulsivity are met for the past 6 months

Source: American Psychiatric Association, DSM-5, 2013 
Table 2

ICD-10 Diagnostic Criteria.

- A behavior disorder in which the essential features are signs of developmentally inappropriate inattention, impulsivity, and hyperactivity.

- A behavior disorder originating in childhood in which the essential features are signs of developmentally inappropriate inattention, impulsivity, and hyperactivity. Although most individuals have symptoms of both inattention and hyperactivity-impulsivity, one or the other pattern may be predominant. The disorder is more frequent in males than females. Onset is in childhood. Symptoms often attenuate during late adolescence, although a minority experience the full complement of symptoms into mid-adulthood.

- A disorder characterized by a marked pattern of inattention and/or hyperactivity-impulsivity that is inconsistent with developmental level and clearly interferes with functioning in at least two settings (e.g., home, school). At least some of the symptoms must be present before the age of 7 years.

Source: https://www.icd10data.com/

\section{Table 3}

Additional ICD-10 Diagnostic Disorders Based on Behavioral and Developmental Problems.

- Specific reading disorder

- Other developmental disorders of scholastic skills

- Developmental disorder of scholastic skills, unspecified

- Conduct disorder confined to family context

- Conduct disorder, childhood-onset type

- Conduct disorder, adolescent-onset type

- Oppositional defiant disorder

- Other conduct disorders

- Conduct disorder, unspecified

- Other childhood emotional disorders

- Childhood emotional disorder, unspecified

- Other childhood disorders of social functioning

- Childhood disorder of social functioning, unspecified

- Unspecified behavioral and emotional disorders with onset usually occurring in childhood and adolescence

- Attention and concentration deficit

Source: https://www.icd10data.com/
The ADHD diagnostic criteria identified by the ICD10 , which includes consideration of the behavioral characteristics for a diagnosis of ADHD in children, are itemized in Table 2. The ICD-10 classification system provides general diagnostic category types including ADHD that is either predominantly Inattention or Hyperactive, along with ADHD that is either Combined or Unspecified. In addition, to further categorize a child's behavior, the ICD-10 provides 15 supplementary codes (see Table 3 ) in a section titled Behavioral and Developmental Disorders.

\section{Medical Symptoms Mimicking ADHD}

In supporting the potential of misdiagnosing ADHD, Saul (2014) identified several medical symptoms that have the capacity to imitate ADHD symptoms due to complaint features that mimic the diagnostic criteria for ADHD. These health-related conditions include difficulties with vision, sleep disturbances, substance abuse, mood disorders (e.g., bipolar, depression), hearing problems, learning disabilities, sensoryprocessing disorders, giftedness, seizure disorder, obsessive-compulsive disorder, Tourette's syndrome, Asperger's syndrome (i.e., an Autism spectrum disorder), neurochemical distractibility/ impulsivity, schizophrenia, fetal alcohol syndrome, and Fragile $\mathrm{X}$ syndrome.

\section{Educational Policy Influences on Diagnoses}

Hinshaw and Scheffler (2014) identified factors associated with educational policies that have contributed to the number of school-aged children who are diagnosed with ADHD. They uncovered a relationship between the rates of ADHD diagnoses and the knowledge that many states changed how schools were budgeted in the 1990s. Specifically, operating funds for schools were distributed based on the number of students reaching set performance measures (e.g., graduation rates, achievement test scores). By the early 2000s, Hinshaw and Scheffler (2014) noted that federal dollars were subjected to the same type of budget management based mainly on student test performance. Together, both these actions at the state and federal levels were highly correlated with increases in the diagnosis of ADHD.

Hinshaw and Scheffler (2014) concluded that the resulting increases in ADHD diagnoses in schoolaged children were caused by two parallel processes that motivated schools to accept children with ADHD as a means of increasing their student numbers. On the one hand, schools with high-performance standards attracted parents who wanted their children with ADHD to attend such schools for treatment 
purposes (Hinshaw \& Scheffler, 2014). Conversely, schools in certain states were permitted to remove children who were diagnosed with ADHD from their performance metrics, which improved the overall achievement ranking of the district (Hinshaw \& Scheffler, 2014). Thus, based on the heightened drive for academic achievement and stricter school accountability, the diagnosis of ADHD rose steeply, particularly, for the neediest children (Hinshaw \& Scheffler, 2014).

\section{Traditional Treatment Approach for ADHD}

Once a child has a diagnosis of ADHD, the next step is generally to determine the type of treatment needed to improve the child's behavior. Treatment approaches to reduce the behavioral symptoms of ADHD in children generally fall into one of two categories, either behavior modification and/or medication.

The results of behavior modification and/or medication interventions have positive outcomes for some children (e.g., Fabiano et al., 2009) and not for others (e.g., Sonuga-Barke et al., 2013). Specifically, in a meta-analysis of non-medication treatment modalities, Sonuga-Barke et al. (2013) did not find substantive positive treatment effects for behavioral interventions in addressing ADHD. However, Fabiano et al. (2009) uncovered support for behavioral interventions, although its long-term results were not evaluated. In a later meta-analysis, Daley et al. (2014) noted that behavioral interventions were associated with several positive benefits including bettering the empowerment of parents and reducing the conduct problems of children diagnosed with ADHD. However, positive outcomes in respect to a child's academic achievements and social skills resulting from behavioral interventions were not substantiated in this review.

For treatments based on the medication approach, several studies have identified concerns regarding the side effects of some of the typical prescriptiondrug regimens. Ellis (2016) discovered the possibility of bone loss (i.e., osteopenia) in children, who were taking methylphenidate (Ritalin), dexmethylphenidate (Focalin), dextroamphetamine (Dexedrine), atomoxetine (Strattera), and lisdexamfetamine (Vyvanse) medications. Nearly $25 \%$ of the children in the Ellis study displayed lower bone-mineral density in the femur, femoral neck, and lumbar spine when they were compared with children who had not taken any of these medications. Ellis also reported additional medication side effects in children consisting of gastrointestinal problems such as decreased appetite and an upset stomach, which could possibly worsen nutrition as well as diminish normal calcium intake. In other research, Brazier (2015) reported that the use of methylphenidate (Ritalin, Concerta, Medikinet, Equasym) resulted in a $60 \%$ higher risk of sleep problems, along with an almost $300 \%$ greater risk of decreased appetite. Poulton et al. (2013) reported height suppression of between 1 to 1.5 inches associated with long-term use of ADHD medication. The MTA study (2004) found that physical growth (height and weight) was diminished in children following 14 months of intensive medication treatment. Additionally, in a long-term follow-up study, Swanson et al. (2017) also found evidence of height suppression in young adults following consistent use of medication from childhood to adulthood. Moreover, in a study of 41 students with ADHD, Steiner, Sheldrick, Gotthelf, and Perrin (2011) found that medication did not have long-lasting effects and that fewer than $50 \%$ of the children remained consistent with their prescribed dosage over a 6-month time frame. Swanson et al. (2017) also noted that consistent use of medication from childhood to adulthood occurred in less than $10 \%$ of ADHD cases and that long-term use was not associated with a reduction in symptom severity in adulthood.

ADHD medication is prescribed to reduce the symptoms of ADHD but does not correct the underlying causes of the behaviors. Remarkably, children are being prescribed medication at younger ages, even as early as preschool age (DSM-5; APA, 2013). Dunlop and Newman (2016) concluded that the use of stimulant medication in children diagnosed with ADHD may be too simple of an approach to treat the complex factors underlying an individual's unregulated behavioral and emotional difficulties.

An incongruity associated with ADHD pharmacological interventions is the existence of a subset of children for whom medications provide little or no improvement in their behavioral functioning (Gleason, 2013; Prasad et al., 2013). Partial cause for a noneffective result may come from rushing some medications to the market place before achieving sufficient scientific documentation (Swanson \& Volkow, 2009). For example, Swanson and Volkow noted that Adderall was reapproved in 1996 as a treatment for ADHD even though there were no controlled randomized clinical trials of its effects on children with ADHD. These authors further commented that despite initial indications of a longterm benefit over the first two treatment years, additional analyses after three treatment years were 
unable to document any long-term relative advantages of the ongoing treatment with stimulants. In addition, a systematic review and meta-analysis conducted by Prasad et al. (2013) of 43 studies involving a pooled-subject total of 2,110 children revealed that drug treatment benefited a child's school performance by at most only $15 \%$, with only a maximum of $14 \%$ of children viewed as being more on-task. The limited benefits of stimulant medication were identified by Gleason (2013) as an important reason to intensify the field's research efforts to identify alternative therapies.

With respect to the long-term benefits of medication treatments in ameliorating the behavioral symptoms of ADHD, Riddle et al. (2013) discovered that nearly $90 \%$ of the 186 children investigated continued to struggle with ADHD symptoms after 6 years of drug treatment. That is, the long-term use of ADHD medications did not result in reduced symptoms in the children who had taken medications (Riddle et al., 2013). Instead, they were found to have symptoms as severe as children who were medication-free (Riddle et al., 2013). A question that arises from these medication limitations is: Why do ADHD symptoms seem to persist following traditional treatment approaches?

\section{The Impact of Inattention}

"Limited processing capacity invariably implies a competition for attention...The term inattention usually implies that, at a given moment, the thing being attended to is either not what it was intended to be or not what adaptively it ought to be. If a single definition could be derived... it would refer...to the state of the individual through which learning takes place. It [attention] makes heavy demands upon the brain's processing capacity" (McCallum, 2015, p. 1516).

Many theories of attention have been postulated over the decades, centuries, and millennia from Greek and Roman philosophers to modern day theorists. Attention has been linked to psychological processing, memory, learning, and perception (Norman, 1982). Processing of information is generally held to be part of the function of attention and memory. In order to understand incoming information, it is necessary to process the information to extract meaning (Norman, 1982). In other words, one must be able to pay attention to be able to respond appropriately. Children who cannot pay attention are thereby unable to respond appropriately to their environmental cues. This inability to attend results in a plethora of difficulties for the child that generates behavioral reactions such as disorganization, lack of follow-through, not listening when spoken to directly, daydreaming, forgetting things, frequently losing things, being easily distracted, lack of focus, or even oppositional defiant disorder, which are common descriptors for children diagnosed with ADHD.

\section{Negative Effects of Processing Problems}

Male students, in particular, can demonstrate restless behaviors or disorganization, or take on the role of the class clown (Woliver \& Ibrahim, 2012), which is often preferred by them rather than feeling rejected because they are unable to learn. For females, their problems may manifest in a different manner and, as a result of less "acting out" behaviors, are not identified as frequently as their male peers as being impaired. Female students may be passed along through school even when they are progressively falling behind in their academic work. In the end, female students may experience greater consequences than their male counterparts, as evidenced by an increased incidence of attempted suicide and other forms of self-injurious behaviors (Chronis-Tuscano et al., 2010; Hinshaw et al., 2012). Regardless of gender, both genders may experience a negative trajectory that has been recognized and documented for children struggling with behaviors associated with ADHD (Lee et al., 2008; Owens et al., 2009). Negative outcomes include a decreased likelihood of completing high school, a higher incidence of involvement with the criminal justice system, and diminished employment outcomes (Breslau, Miller, Chung, \& Schweitzer, 2011; Hinshaw \& Ellison, 2016; Pingault et al., 2011).

Children who are unable to follow through on instructions and requests even with repeated instructions or who cannot organize tasks typically experience greater levels of frustration. Increased levels of frustration often result in negative behaviors leading to behavioral dysregulation, acting-out behaviors, and a diminished sense of self.

\section{Behavior Is a Form of Communication}

Children are not always able to effectively verbally communicate the difficulties they are experiencing. One of the communication tools of a child is their behavior. When behaviors are seen as problematic, parents and teachers seek to reduce or eliminate the unwanted behavior. Although there is evidence that behavioral interventions have positive outcomes for some children (Evans, Owens, \& Bunford, 2014), the goal of behavioral interventions is to reduce or eliminate the unwanted behaviors. However, there 
may be useful information that the child is communicating through these "problematic" behaviors that requires the understanding of parents and teachers - and may be the child's only means to receive the help that he or she needs.

By considering that problematic behaviors are a type of language to be decoded, a shift occurs in the perception of the observed "negative" behaviors. In considering that behavior is a form of communication, behaviors can provide information about what the child is struggling with in his or her life at home and at school. Shifting from attempting to reduce the negative behaviors using traditional medication or behavioral interventions to identifying the underlying cause of the behavioral symptoms creates an alternative approach to working with the child. Developing a greater understanding of the auditory and/or visual processing difficulties the child is experiencing provides a different context within which to apply a different intervention; namely, one that corrects the underlying auditory and visual processing difficulties. This shift has the potential to yield positive benefits for all involved - the child, the teacher, and the parents.

\section{Auditory Processing Difficulties}

Children who have auditory processing difficulties (APD) may engage in behaviors that mimic the behavioral symptoms of ADHD (Gyldenkærne, Dillon, Sharma, \& Purdy, 2014). APD is not about hearing loss, typically identified through audiological assessments, but rather concerns how the brain is processing auditory stimuli. Distinguished from Central Auditory Processing Disorder (CAPD), Chermak and Musiek (1997) postulated that CAPD is an input disorder impeding selective and divided auditory attention, while ADHD is an output disorder causing sustained attention deficits across modalities.

Tomlin, Dillon, Sharma, and Rance (2015) identified the need for better assessment measures to ferret out APD and cognitive limitations in children when attempting to determine causality of APD. Furthermore, Sharma, Purdy, and Kelly (2009) concluded that assessing central auditory processing, language and reading disorders did not provide a full explanation of auditory processing difficulties. Some identified symptoms of APD are noted in Table 4.

Children with APD may have difficulty learning when they are being taught in a noisy classroom environment (Behavioural Neurotherapy Clinic, 2016; Moore, Ferguson, Edmondson-Jones, Ratib \& Riley,
2010) and may be unable to follow along in a conversation or remember what is said to them when asked to perform multi-stepped tasks. Instructions must be repeated multiple times and still the child does not follow through with the requested tasks in home and school environments. Because of APD, children may define themselves as less intelligent and lose confidence in themselves. Children with APD may engage in disruptive behaviors (Woliver \& Ibrahim, 2012), and some may find it better to be labeled a "problem child" (Swingle, 2015, p. 106) than incapable or, even worse, as "slow."

\section{Table 4}

Auditory Processing Difficulties.

- Difficulty hearing in noisy environments

- Difficulty following long conversations

- Problems with reading comprehension

- Trouble understanding verbal math problems

- Difficulty remembering spoken information (i.e., auditory memory deficits)

- Difficulty taking notes

- Difficulty maintaining focus on an activity if other sounds are present

- Easily distracted by other sounds in the environment

- Difficulty with organizational skills

- Difficulty following multi-step directions

- Difficulty in directing, sustaining, or dividing attention

- Difficulty with reading and/or spelling

- Difficulty processing nonverbal information

- Anxiety, which might lead to illnesses such as irritable bowel syndrome or panic attacks

Source: American Academy of Audiology, 2010

\section{Visual Processing Difficulties}

Visual processing difficulties (VPD) are not about nearsightedness or farsightedness, but rather speak to how a child's brain processes visual information (Epstein, 2015). Children who have VPD may have difficulties remaining attentive to visual tasks. Farrar, Call, and Maples (2001) discovered that children diagnosed with ADHD have problems with visual memory and spatial orientation. Hagen, Moore, Wickham, and Maples (2008) found that children who have trouble with visual skills have difficulty with attention, which interferes with executive brain functioning and mimics ADHD symptoms. Children with VPD may be easily distracted by too much visual stimulation. 
Some of the identified VPD symptoms include those noted in Table 5. Children who have VPD may demonstrate difficulty in remembering information that has been shown to them. They also may struggle with remembering letters and numbers, as if they have a short- or long-term memory problem (Epstein, 2015).

\section{Table 5}

Visual Processing Difficulties.

- May exhibit difficulty with tasks that require copying (e.g., taking notes from a whiteboard)

- Written copies may be missing words

- Often cannot remember even basic facts about material read silently

- Complains of eye strain or frequently rubs eyes despite no presence of poor eye sight

- Below average reading or writing level coupled with high oral comprehension and verbal skills

- Math skills may be demonstrated below average, may ignore function signs, omit steps or confuse visually similar formulae

- Routinely fails to observe or recognize changes in bulletin-board displays, signs, or posted notices

Source: New Brunswick Department of Education, 1999

\section{Identifying Auditory and Visual Processing}

Difficulties

The Integrated Visual and Auditory Continuous Performance Test - Version 2 (IVA-2; Sandford \& Sandford, 2014) supports clinicians in their efforts to identify an individual's strengths and weaknesses in visual and auditory processing (Sandford \& Sandford, 2014). Although the ability to discriminate between APD and ADHD has yet to be fully established in the treatment of ADHD, Gyldenkærne et al. (2014) uncovered some degree of correlation between APD and ADHD measures. However, "even though deficits in both APD and maintained attention cooccur in more children than would be expected from chance alone, the two conditions are separate and largely independent conditions, even though they may have similar symptoms" (Gyldenkærne et al., 2014 , p. 676). Determining whether or not auditory and visual processing difficulties are a function of ADHD, or if ADHD has become a catchment category for auditory and visual processing difficulties, remains inconclusive.

Regardless of how auditory and visual processing difficulties are categorized, when a child cannot process what is being said to him or her regardless of the number of times the auditory and/or visual information is repeated, something is interfering with the child's ability to do so. Children generally want to succeed in school, and they want to have positive relationships with their parents, peers, and teachers. They want to have a better life and they want to do well. Yet many are unable to achieve these goals, despite their best efforts. Identifying and strengthening APD and VPD processes in children may lead to a reduction in problematic behaviors, yielding improvements both at home and at school. Based on our clinic work with children who have auditory and visual processing difficulties, often associated with an ADHD diagnosis, the results of this work are reported and discussed in the following sections.

Table 6 lists some of the behavioral symptoms identified with the IVA-2 assessment in children who have auditory/visual attentional difficulties.

\section{Table 6}

Symptoms of Auditory/Visual Processing Deficits Identified via IVA-2.

- Significant problems remaining alert (i.e., likely to tune out)

- $\quad$ Problems shifting sets (i.e., likely to drift off)

- Difficulty getting back on track when distracted by auditory or visual stimuli

- Deficits in auditory or visual working memory

- Difficulty in maintaining focus to auditory or visual stimuli

- Difficulty following directions accurately

- Misunderstanding verbal instructions

- Problems with self-esteem or self-confidence

- Erratic responses to auditory and/or visual stimuli (i.e., makes more errors when high demand to perform)

- Frequent lapses in visual or auditory attention

- Rushes through written work resulting in careless errors

- Attention problems related to slow mental processing

- Problems with response inhibition and impulse control tendencies reflecting carelessness, thoughtlessness, or overreactivity

- Problems regulating and directing actions when stressed or tired (i.e., gives up)

- Acting out, irritability, and negative verbalizations

- Impaired social interactions with peers 


\section{Table 6 (continued)}

Symptoms of Auditory/Visual Processing Deficits Identified via IVA-2.

- Trouble with self-direction and completing necessary work

- Tendencies reflecting distractible, divergent or variable attention processing when given a repetitive, demanding, structured, nonentertaining task

- Difficulties learning new tasks in the school environment

- Slow mental processing speed

- Problems sustaining attention and responding in a consistent manner when asked questions verbally or given written tests

- Starts tasks then quickly runs out of steam; may be very slow in getting the work done that needs to be completed

- Impulsive, agitated, chaotic, overexcited, and turbulent

- Significant problems with self-control

- Difficulty listening, remembering, or following rules

- Agitated, confused, or excessively impulsive response pattern

- Internally distracted to the point there is difficulty concentrating and performing meaningful mental activities

- Significant trouble with test performance

Source: IVA-2, Sandford \& Sandford, 2014

\section{Methods}

\section{Participants}

Neurofeedback treatment was provided for 51 children ( $n=35$ males, $n=16$ females, ages 6 to 17$)$ who completed a total of 40 half-hour sessions of neurofeedback treatment. The participants for this study were randomly drawn from an archival database of children who had previously received individualized neurofeedback training within a university-based clinic setting. Only those children who completed 40 neurofeedback treatment sessions and were identified by the IVA-2 comprehensive diagnostic algorithm to have manifested significant ADHD symptomatology were selected for this study.

Participants were brought in by a parent or guardian and informed consent was obtained prior to starting the treatment. Clinical neurofeedback services were provided to participants based on a sliding fee scale and since this was an archival study they were not compensated. This study was approved by the
California State University San Bernardino Institutional Review Board.

\section{Measurements}

The IVA-2 CPT has been found to be a valid and reliable measure of both visual and auditory attention functioning for children and adults and provides global and primary measures of attentional functioning. The normative sample, with approximately equal numbers of males and females, included 1,700 individuals ages 6 to 96 (Maddux, 2010). Furthermore, the IVA-2 provides both global and primary measures of attentional functioning that assess auditory and visual attention processing. All IVA-2 scale scores have a mean of 100 and a standard deviation of 15 (Sandford \& Sandford, 2014).

The IVA-2 global and standard measures of attention used in this study are the Auditory Attention Quotient (AAQ), Visual Attention Quotient (VAQ), Full Scale Attention Quotient (FAQ), Auditory Response Control Quotient (ARCQ), Visual Response Control Quotient (VRCQ), Full Scale Response Control Quotient (FRCQ), Sustained Auditory Attention Quotient (SAAQ), Sustained Visual Attention Quotient (SVAQ), and the Sustained Full Scale Attention Quotient (SFAQ; Sandford \& Sandford, 2014; see Appendix for scale descriptions).

The Auditory Attention Quotient (AAQ) is a global measure of attention comprised of three primary visual and auditory scales: Vigilance, Speed, and Focus. Vigilance measures errors of omission, and Speed provides a measure of the response time in milliseconds to visual and auditory stimuli targets. Focus is a measure of the variability of response time to auditory test targets. The Visual Attention Quotient (VAQ) is based on the exact same scales as the AAQ but differs in that it assesses visual test responses to the same measures of attention. The FAQ is a global composite scale comprised of the $A A Q$ and $V A Q$ scales, which are used in equal weights (not an average) to determine the FAQ (Sandford \& Sandford, 2014).

The Auditory Response Control Quotient (ARCQ) is a global measure comprised of three response control scales: Prudence, Consistency, and Stamina. Prudence measures impulsivity and response inhibition as evidenced by three different types of errors of commission. Consistency measures the general variability of response times ignoring outliers and is a measure of the ability to stay on task. Stamina compares the mean reaction times of correct 
responses between the first and last half of the IVA-2 test and is used to identify an individual's problems related to fatigue in mental processing speed over time. The Visual Response Control Quotient (VRCQ) has the exact same component scales as ARCQ but differs in that it specifically assesses visual test responses. The FRCQ is a composite scale comprised of the ARCQ and VRCQ scales; it is the combined measure of the auditory and visual primary scales that assess impulsivity, consistency of response time and performance stamina during the test (Sandford \& Sandford, 2014).

The Sustained Auditory Attention Quotient (SAAQ) provides a global measure of a person's ability to respond to auditory stimuli under low demand conditions accurately, quickly, and reliably, and it is combined with an assessment of the person's ability to sustain attention and be flexible under high demand conditions when auditory stimuli change frequently. It is comprised of the following primary scales: Acuity, Dependability, Elasticity, Reliability, Steadiness, and Swiftness. Acuity measures errors of omission under low demand conditions, Dependability reflects the variability of reaction times under low demand conditions, Elasticity reflects the ability to be flexible when faced with changing conditions, Reliability measures idiopathic errors of commission, Steadiness is a measure of accuracy under high demand conditions, and Swiftness measures response times under low demand conditions when the targets are rare. The Sustained Visual Attention Quotient (SVAQ) measures the exact same type of factors as SAAQ, but specifically for visual test responses. The Sustained Full Scale Attention Quotient (SFAQ) is the combined weighted global measure of the SAAQ and SVAQ global scales (Sandford \& Sandford, 2014).

\section{Test Procedures}

Every participant was administered the IVA-2 CPT before beginning their first neurofeedback session. Testing was individually administered and scored in accordance with the specified test guidelines. Some individuals were not able to validly respond to either visual or auditory IVA-2 test stimuli due to their extreme deficits in attentional functioning. In these cases, their "invalid scores" for IVA-2 were scored as zero in accordance with the recommended test interpretive procedures (Sandford \& Sandford, 2014). After the completion of both 20 and 40 neurofeedback sessions, the IVA-2 was readministered. Fifty-one participants completed 40 neurofeedback sessions. The IVA-2 data was analyzed comparing baseline test scores and the scores obtained after the 20th and 40th neurofeedback sessions were completed.

\section{Neurofeedback Treatment Protocols}

An individualized neurofeedback training plan was developed for each participant and modified as necessary. Treatment was provided on a one-to-one basis in a private room setting. Therapeutic goals focused on improving auditory and/or visual attentional functioning and reducing any identified behavioral-related symptoms of anxiety or fine motor hyperactivity. Training was completed using the SmartMind 3 artifact-corrected neurofeedback system with a two-channel EEG station (BrainTrain, Inc., North Chesterfield, Virginia) which continuously filters out both brief facial activity, as well as frequently occurring eye-blink and eye-movement artifacts in real time without interrupting the training program. As conducted in a McReynolds, Bell, and Lincourt (2017) study, neurofeedback exercises were provided in game-like format that utilized both visual and auditory reinforcement, as well as graphs and numerical scores to provide positive reinforcement. The first step in the training session was to collect participants' baseline EEG data to determine Z-score feedback goals for each participant. Based on each individual's performance, they were provided clinically relevant feedback and adjustments were made to the training protocol to optimize their performance. Sensors were attached and secured using 10-20 electrode paste and electrode rings after the site locations were prepared. Impedance was checked to meet the manufacturer's requirements prior to the beginning of training. All EEG data was automatically deartifacted and recorded by the SmartMind 3 software.

\section{Results}

The three main global scale scores that measured combined changes in auditory and visual general attention (FAQ), sustained attention (SFAQ), and response control (FRCQ) comprised the first step of evaluation. These three tests were correlated .54 and a Bonferroni correction was calculated taking into account the correlation using an alpha criterion of .05 . The IVA-2 scores of these three scales were collected at baseline, and after 20 and 40 sessions were completed. This resulted in a determination that the $p$ value test of significance criterion needed to be .03 for the nine paired $t$-tests that were completed. Given that it was expected based on past research studies that neurofeedback would result in positive changes in both auditory and visual attention, one-tail $t$-test values were used in assessing significance. Since 
the normative mean quotient score of the IVA-2 test is 100 and its standard deviation is 15 , any change or difference of 8 or more quotient score points (i.e., greater than one half of a standard deviation) was considered to be of clinical significance. In order to evaluate whether neurofeedback training improves auditory and visual attention, paired sample t-tests were computed comparing the changes for the IVA-2 $F A Q, S F A Q$, and FRCQ global scale scores by comparing the scores between the baseline, after 20 sessions, after 40 sessions, and between 20 and 40 sessions.

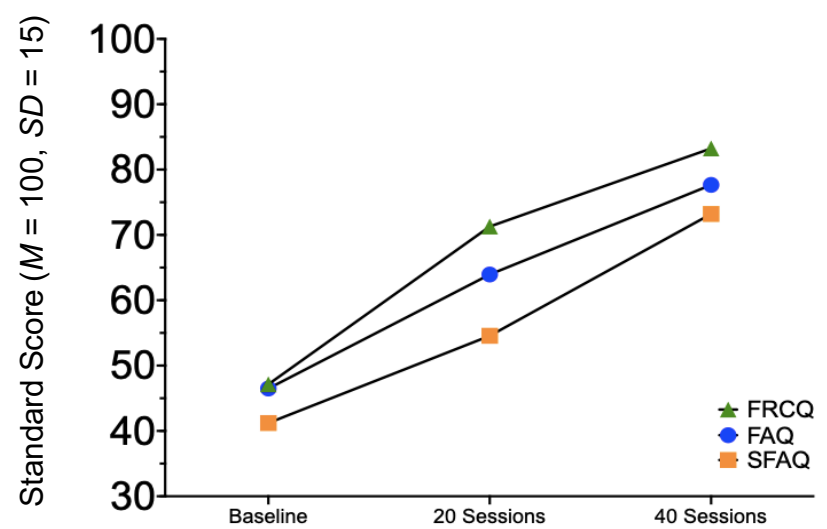

Figure 1. IVA-2 Global Combined Scale Score Changes During Training for FRCQ (Full-scale Response Control Quotient, 20 Sessions, $p<.001$, Cohen's $d=0.61 ; 20-40$ Sessions, $p<.01$, Cohen's $d=0.33$ ); FAQ (Full Scale Attention Quotient, 20 Sessions, $p<.001$, Cohen's $d=0.45$; 20-40 Sessions $p<.01$, Cohen's $d=0.37$ ); SFAQ (Sustained Full-scale Attention Quotient, 20 Sessions, $p<.01$, Cohen's $d=0.34 ; 20-40$ Sessions, $p<.001$, Cohen's $d=0.48$ ). See Tables 7, 8, 9.

As indicated in Figure 1 (see Tables 7, 8, 9), children significantly increased their Global Combined Scale Scores for FRCQ. Scores were found to be significantly higher after 20 sessions of treatment from a mean of 47 (Extremely Impaired) to 71 (Moderately to Severely Impaired), a 24-point increase, $t(50)=-4.59, p<.001$, Cohen's $d=0.61$; FRCQ scores from 20 to 40 sessions of treatment significantly improved from a mean of 71 (Moderately to Severely Impaired) to 83 (Mildly Impaired), a 12point increase, $t(50)=-2.79, p<.01$, Cohen's $d=$ 0.33; overall, FRCQ scores between baseline and 40 sessions reflected a significant improvement from a mean of 47 (Extremely Impaired) to 83 (Mildly Impaired), a 36-point improvement, $t(50)=-6.22, p$ $<.001$, Cohen's $d=0.93$.

FAQ scores were found to be significantly higher after 20 sessions of treatment from a mean of 47 (Extremely Impaired) to 64 (Severely Impaired), a 17point increase, $t(50)=-3.48, p<.001$, Cohen's $d=$ 0.45 ; FAQ scores from 20 to 40 sessions improved from a mean of 64 (Severely Impaired) to 78 (Mildly to Moderately Impaired), a 14-point increase, $t(50)=$ $-3.25, p<.01$, Cohen's $d=0.37$; overall, FAQ scores between baseline and 40 sessions reflected a significant improvement from a mean of 47 (Severely Impaired) to 78 (Mildly to Moderately Impaired), $t(50)$ $=-5.35, p<.001$, Cohen's $d=0.82$, a 31-point improvement.

SFAQ scores were found to be significantly higher after 20 sessions of treatment from a mean of 41 (Extremely Impaired) to 55 (Extremely Impaired), a 14-point increase, $t(50)=-2.51, p<.01$, Cohen's $d=$ 0.34 ; SFAQ scores from 20 to 40 sessions of treatment significantly improved from a mean of 55 (Extremely Impaired) to 73 (Moderately Impaired), an 18-point increase, $t(50)=-4.11, p<.001$, Cohen's $d$ $=0.48$; overall, SFAQ scores between baseline and 40 sessions reflected a significant improvement from a mean of 41 (Extremely Impaired) to 73 (Moderately Impaired), a 32-point improvement, $t(50)=-5.43, p$ $<.001$, Cohen's $d=0.85$ (see Table 7 for baseline to 20, Table 8 for 20 to 40, and Table 9 for Baseline to 40).

\section{Table 7}

Paired t-tests comparing changes in the mean IVA-2 main global measures of attention and response control scale scores between baseline and after completion of 20 neurofeedback sessions.

\begin{tabular}{lcccccc}
\hline $\begin{array}{l}\text { IVA-2 Attention } \\
\text { Scales }\end{array}$ & Baseline & 20 Sessions & $\begin{array}{l}\text { Q Score } \\
\text { Change }\end{array}$ & Pooled SD & Sig. & Cohen's $d$ \\
\hline FAQ & 47 & 64 & 17 & 39.09 & .001 & 0.45 \\
SFAQ & 41 & 55 & 14 & 39.15 & .01 & 0.34 \\
FRCQ & 47 & 71 & 24 & 39.83 & .001 & 0.61 \\
\hline
\end{tabular}




\section{Table 8}

Paired t-tests comparing changes in the mean IVA-2 main global measures of attention and response control scale scores between 20 sessions and after completion of 40 neurofeedback sessions.

\begin{tabular}{lcccccc}
\hline $\begin{array}{l}\text { IVA-2 Attention } \\
\text { Scales }\end{array}$ & 20 Sessions & 40 Sessions & $\begin{array}{l}\text { Q Score } \\
\text { Change }\end{array}$ & Pooled SD & Sig. & Cohen's $d$ \\
\hline FAQ & 64 & 78 & 14 & 36.64 & .01 & 0.37 \\
SFAQ & 55 & 73 & 18 & 39.00 & .001 & 0.48 \\
FRCQ & 71 & 83 & 12 & 36.13 & .01 & 0.33 \\
\hline
\end{tabular}

\section{Table 9}

Paired t-tests comparing changes in the mean IVA-2 main global measures of attention and response control scale scores between baseline and after completion of 40 neurofeedback sessions.

\begin{tabular}{lcccccc}
\hline $\begin{array}{l}\text { IVA-2 Attention } \\
\text { Scales }\end{array}$ & Baseline & 40 Sessions & $\begin{array}{c}\text { Q Score } \\
\text { Change }\end{array}$ & Pooled SD & Sig. & Cohen's $d$ \\
\hline FAQ & 47 & 78 & 31 & 37.90 & .001 & 0.82 \\
SFAQ & 41 & 73 & 32 & 37.62 & .001 & 0.85 \\
FRCQ & 47 & 83 & 36 & 38.67 & .001 & 0.93 \\
\hline
\end{tabular}

In Figure 1, the continued improvement in global attention and response control from 20 to 40 sessions that was significant can be viewed across the FRCQ and SFAQ global measures. Scores on the FRCQ were found to be significantly higher after 20 sessions of treatment with a 14-point increase and significantly higher with an 18-point increase after 40 sessions. The SFAQ global scale scores were found to be significantly higher after 20 sessions of treatment with a 14-point increase and significantly higher with an 18-point increase after 40 sessions. The FAQ test scores significantly increased 17 points from baseline to 20 sessions; however, unlike the FRCQ and the SFAQ, the FAQ showed a 14-point change from 20 to 40 sessions.

The FAQ, SFAQ, and FRCQ are combined global scales based on each of their two respective auditory and visual global scales. General attention, sustained attention and response control global scale scores improved at 20 sessions with small to medium size effects, and all three global measures continued to significantly improve after an additional 20 sessions of training, resulting in neurofeedback treatment significantly improving attention and selfcontrol after additional training with large size effects (i.e., $>2$ SDs).

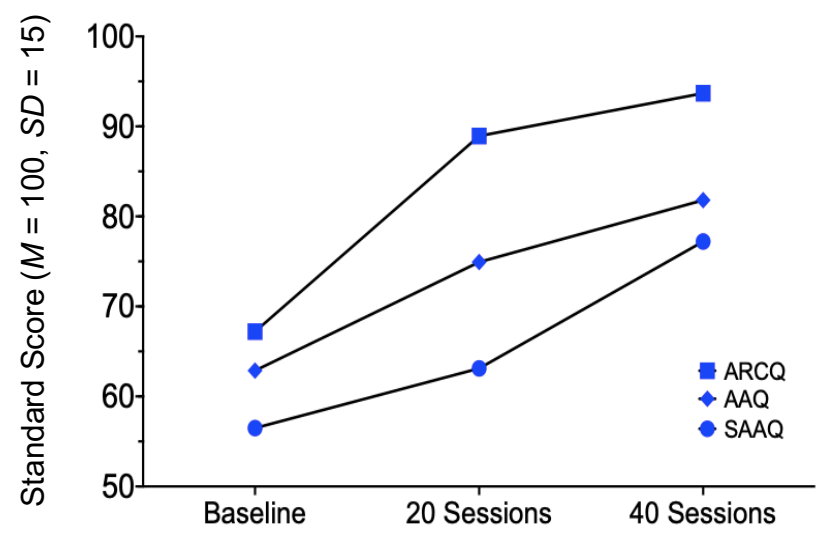

Figure 2. IVA-2 Auditory Scale Score Changes During Training for ARCQ (Auditory Response Control Quotient, 20 Sessions, $p<.001$, Cohen's $d=0.73 ; 20-40$ Sessions, $p>.10$, Cohen's $d=0.21$ ); AAQ (Auditory Attention Quotient, 20 Sessions, $p<.01$, Cohen's $d=0.37$; 20-40 Sessions, $p<.05$, Cohen's $d=0.23$ ); SAAQ (Sustained Auditory Attention Quotient, 20 Sessions, $p>.10$, Cohen's $d=0.18 ; 20-40$ Sessions, $p<.01$, Cohen's $d=0.40$ ). See Tables 10, 11, 12.

As indicated in Figure 2, ARCQ scores were found to be significantly higher after 20 sessions of treatment from a mean of 67 (Severely Impaired) to 89 (Slightly Impaired), a 22-point increase, $t(50)=-4.5, p<.001$, Cohen's $d=0.73$; ARCQ scores from 20 to 40 sessions of treatment normalized from a mean of 89 (Slightly Impaired) to 94 (Average), a 5-point 
increase, $t(50)=-1.18, p>.10$, Cohen's $d=0.21$; overall, ARCQ scores between baseline and 40 sessions reflected a significant improvement from a mean of 67 (Severely Impaired) to 94 (Average), a 27point improvement, $t(50)=-4.63, p<.001$, Cohen's $d=0.81$.

$A A Q$ scores were also found to be significantly higher after 20 sessions of treatment from a mean of 63 (Severely Impaired) to 75 (Moderately Impaired), a 12-point increase, $t(50)=-2.45, p<.01$, Cohen's $d=$ 0.37 ; AAQ scores from 20 to 40 sessions of treatment improved from a mean of 75 (Moderately Impaired) to 82 (Mildly Impaired), a 7-point increase, $t(50)=-1.75$, $p<.05$, Cohen's $d=0.23$; overall, AAQ scores between baseline and 40 sessions reflected a significant improvement from a mean of 63 (Severely Impaired) to 82 (Mildly Impaired), a 19-point improvement, $t(50)=-3.68, p<.001$, Cohen's $d=$ 0.57 .

SAAQ scores were found to be improved after 20 sessions of treatment from a mean of 56 (Extremely Impaired) to 63 (Severely Impaired), a 7-point increase, $t(50)=-1.21, p>.10$, Cohen's $d=0.18$; SAAQ scores from 20 to 40 sessions of treatment significantly improved from a mean of 63 (Severely Impaired) to 77 (Mildly to Moderately Impaired), a 14point increase, $t(50)=-2.66, p<.01$, Cohen's $d=$ 0.40 ; overall, SAAQ scores between baseline and 40 sessions reflected a significant improvement from a mean of 56 (Extremely Impaired) to 77 (Mildly to Moderately Impaired), a 21-point improvement, $t(50)$ $=-3.59, p<.001$, Cohen's $d=0.57$ (see Tables 10, $11,12)$

\section{Table 10}

Paired t-tests comparing changes in the mean IVA-2 main global measures of auditory attention and response control scale scores between baseline and after completion of 20 neurofeedback sessions.

\begin{tabular}{lcccccc}
\hline $\begin{array}{l}\text { IVA-2 Attention } \\
\text { Scales }\end{array}$ & Baseline & 20 Sessions & $\begin{array}{c}\text { Q Score } \\
\text { Change }\end{array}$ & Pooled SD & Sig. & Cohen's $d$ \\
\hline AAQ & 63 & 75 & 12 & 32.81 & .01 & 0.37 \\
SAAQ & 56 & 63 & 7 & 36.89 & .10 & 0.18 \\
ARCQ & 67 & 89 & 22 & 29.74 & .001 & 0.73 \\
\hline
\end{tabular}

\section{Table 11}

Paired t-tests comparing changes in the mean IVA-2 main global measures of auditory attention and response control scale scores between 20 sessions and after completion of 40 neurofeedback sessions.

\begin{tabular}{lcccccc}
\hline $\begin{array}{l}\text { IVA-2 Attention } \\
\text { Scales }\end{array}$ & 20 Sessions & 40 Sessions & $\begin{array}{l}\text { Q Score } \\
\text { Change }\end{array}$ & Pooled SD & Sig. & Cohen's $d$ \\
\hline AAQ & 75 & 82 & 7 & 29.40 & .05 & 0.23 \\
SAAQ & 63 & 77 & 14 & 35.39 & .01 & 0.40 \\
ARCQ & 89 & 94 & 5 & 23.01 & .10 & 0.21 \\
\hline
\end{tabular}

\section{Table 12}

Paired t-tests comparing changes in the mean IVA-2 main global measures of auditory attention and response control scale scores between baseline and after completion of 40 neurofeedback sessions.

\begin{tabular}{lcccccc}
\hline $\begin{array}{l}\text { IVA-2 Attention } \\
\text { Scales }\end{array}$ & Baseline & 40 Sessions & $\begin{array}{l}\text { Q Score } \\
\text { Change }\end{array}$ & Pooled SD & Sig. & Cohen's $d$ \\
\hline AAQ & 63 & 82 & 19 & 32.99 & .001 & 0.57 \\
SAAQ & 56 & 77 & 21 & 36.08 & .001 & 0.57 \\
ARCQ & 67 & 94 & 27 & 32.67 & .001 & 0.81 \\
\hline
\end{tabular}


In Figure 2, the continued improvement in auditory attention and auditory response control from 20 to 40 sessions that was significant can be viewed across all three global auditory measures. The ARCQ test scores significantly increased 22 points after 20 sessions and increased 5 points after 40 sessions, reflecting that significant change occurred from baseline to 20 sessions. Scores on the AAQ were found to be significantly higher from baseline to 20 sessions of treatment with a 12-point increase and a 7-point increase after 40 sessions, reflecting significant change occurred on the AAQ global scale at 20 sessions. The SAAQ global scale scores increased 7 points after 20 sessions of treatment and was significantly higher with a 14-point increase after 40 sessions, reflecting that significant change occurred following 40 sessions.

Auditory attention (AAQ) global scale (Vigilance, Focus, and Speed) were in the Severely Impaired range at baseline and normalized to the Mildly Impaired range at 40 sessions. ARCQ (Prudence, Consistency, and Stamina) scores were in the Severely Impaired range at baseline and normalized to the Average range following 40 sessions of treatment. SAAQ (Inattention) scores were in the Extremely Impaired range at baseline and were in the Mildly to Moderately Impaired range following 40 sessions of treatment.

As indicated in Figure 3, VRCQ scores were found to be significantly higher after 20 sessions of treatment from a mean of 54 (Extremely Impaired) to 72 (Moderately Impaired), an 18-point increase, $t(50)=$ $-3.20, p<.01$, Cohen's $d=0.45$; VRCQ scores from 20 to 40 sessions of treatment significantly improved from a mean of 72 (Moderately Impaired) to 81 (Mildly Impaired), a 9-point increase, $t(50)=-2.11, p<.02$, Cohen's $d=0.26$; overall, VRCQ scores between baseline and 40 sessions reflected a significant improvement from a mean of 54 (Extremely Impaired) to 81 (Mildly Impaired), a 27-point improvement, $t(50)$ $=-4.35, p<.001$, Cohen's $d=0.69$.

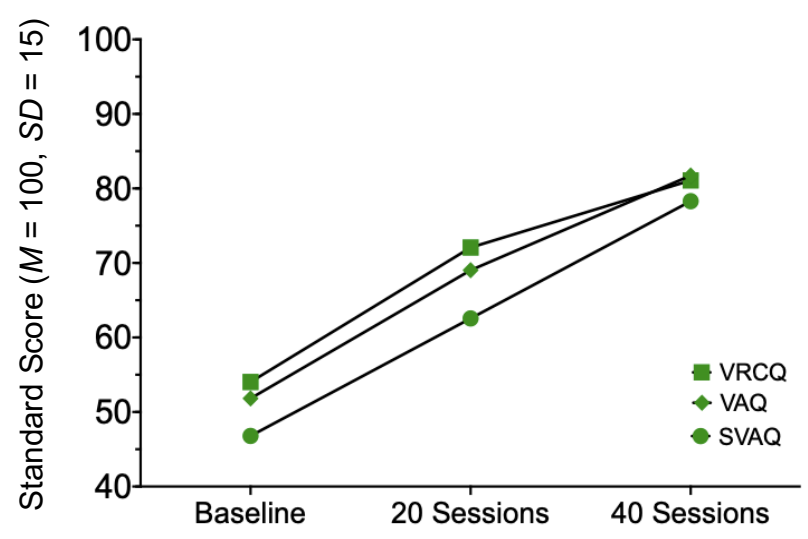

Figure 3. IVA-2 Visual Scale Score Changes During Training for VRCQ (Visual Response Control Quotient, 20 Sessions, $p<.01$, Cohen's $d=0.45 ; 20-40$ Sessions, $p<.02$, Cohen's $d=0.26$ ); VAQ (Visual Attention Quotient, 20 Sessions, $p<.01$, Cohen's $d=0.43 ; 20-40$ Sessions, $p<.01$, Cohen's $d=0.35$ ); SVAQ (Sustained Visual Attention Quotient, 20 Sessions, $p<.01$, Cohen's $d=0.39$; $20-40$ Sessions, $p<.001$, Cohen's $d=0.41$ ). See Tables 13, 14, 15.

VAQ scores were found to be significantly higher after 20 sessions of treatment from a mean of 52 (Extremely Impaired) to 69 (Moderately to Severely Impaired), a 17-point increase, $t(50)=-3.03, p<.01$, Cohen's $d=0.43$; VAQ scores from 20 to 40 sessions of treatment significantly improved from a mean of 69 (Moderately to Severely Impaired) to 82 (Mildly Impaired), a 13-point increase, $t(50)=-2.83, p<.01$, Cohen's $d=0.35$; overall, VAQ scores between baseline and 40 sessions reflected a significant improvement from a mean of 52 (Extremely Impaired) to 82 (Mildly Impaired), a 30-point improvement, $t(50)$ $=-4.64, p<.001$, Cohen's $d=0.77$.

SVAQ scores were found to be significantly higher after 20 sessions of treatment from a mean of 47 (Extremely Impaired) to 63 (Severely Impaired), a 16point increase, $t(50)=-2.53, p<.01$, Cohen's $d=$ 0.39; SVAQ scores from 20 to 40 sessions of treatment significantly improved from a mean of 63 (Severely Impaired) to 78 (Mildly to Moderately Impaired), a 13-point increase, $t(50)=-3.33, p$ $<.001$, Cohen's $d=0.41$; overall, SVAQ scores between baseline and 40 sessions reflected a significant improvement from a mean of 47 (Extremely Impaired) to 78 (Mildly to Moderately Impaired), a 31-point improvement, $t(50)=-4.76, p$ $<.001$, Cohen's $d=0.82$ (see Tables 13, 14, 15). 


\section{Table 13}

Paired t-tests comparing changes in the mean IVA-2 main global measures of visual attention and response control scale scores between baseline and after completion of 20 neurofeedback sessions.

\begin{tabular}{lcccccc}
\hline $\begin{array}{l}\text { IVA-2 Attention } \\
\text { Scales }\end{array}$ & Baseline & 20 Sessions & $\begin{array}{l}\text { Q Score } \\
\text { Change }\end{array}$ & Pooled SD & Sig. & Cohen's $d$ \\
\hline VAQ & 52 & 69 & 17 & 39.88 & .01 & 0.43 \\
SVAQ & 47 & 63 & 16 & 40.82 & .01 & 0.39 \\
VRCQ & 54 & 72 & 18 & 40.13 & .01 & 0.45 \\
\hline
\end{tabular}

Table 14

Paired t-tests comparing changes in the mean IVA-2 main global measures of visual attention and response control scale scores between 20 sessions and after completion of 40 neurofeedback sessions.

\begin{tabular}{lcccccc}
\hline $\begin{array}{l}\text { IVA-2 Attention } \\
\text { Scales }\end{array}$ & 20 Sessions & 40 Sessions & $\begin{array}{l}\text { Q Score } \\
\text { Change }\end{array}$ & Pooled SD & Sig. & Cohen's $d$ \\
\hline VAQ & 69 & 82 & 13 & 36.84 & .01 & 0.35 \\
SVAQ & 63 & 78 & 15 & 38.77 & .001 & 0.41 \\
VRCQ & 72 & 81 & 9 & 35.33 & .02 & 0.26 \\
\hline
\end{tabular}

\begin{tabular}{lcccccc}
\hline $\begin{array}{l}\text { Table 15 } \\
\text { Paired t-tests comparing changes in the mean IVA-2 main } \\
\text { control scale scores between baseline and after completion of } 40 \text { neurofeedback sessions. }\end{array}$ \\
$\begin{array}{l}\text { IVA-2 Attention } \\
\text { Scales }\end{array}$ & Baseline & 40 Sessions & $\begin{array}{l}\text { Q Score } \\
\text { Change }\end{array}$ & Pooled SD & Sig. & Cohen's d \\
\hline VAQ & 52 & 82 & 30 & 38.79 & .001 & 0.77 \\
SVAQ & 47 & 78 & 31 & 38.51 & .001 & 0.82 \\
VRCQ & 54 & 81 & 27 & 39.03 & .001 & 0.69 \\
\hline
\end{tabular}

In Figure 3, the continued improvement in auditory attention from 20 to 40 sessions that was significant can be viewed across all three global visual attention and response control measures. The VRCQ global scale scores increased 18 points from baseline to 20 sessions of treatment and increased 9 points after 40 sessions reflecting that significant change occurred after 20 and 40 sessions. Scores on the VAQ were found to be significantly higher from baseline to 20 sessions of treatment with a 17-point increase followed by a 13-point increase after 40 sessions reflecting significant change occurred on the visual global scales of attention after 20 and 40 sessions. The SVAQ test scores significantly increased 16 points after 20 sessions and increased 13 points after 40 sessions reflecting significant change occurred at 20 and 40 sessions.
Visual attention (VAQ) global scale (Vigilance, Focus, and Speed) were in the Extremely Impaired range at baseline and normalized to the Mildly Impaired range at 40 sessions. VRCQ (Prudence, Consistency, and Stamina) scores were in the Extremely Impaired range at baseline and normalized to the Mildly Impaired range following 40 sessions of treatment. SVAQ (Inattention) scores were in the Extremely Impaired at baseline and were in the Mildly to Moderately Impaired range following 40 sessions of treatment. Thus, these test results support the hypothesis that artifact-corrected neurofeedback training led to a significant improvement in global measures of both auditory and visual attention. 


\section{Discussion}

Neurofeedback therapy, or EEG biofeedback, has been widely used for more than 40 years. During this time, it has gained recognition as an acceptable approach for treating conditions ranging from ADHD to anxiety, depression, sleep disorders, and learning disabilities (Hammond, 2011). For children identified as having impaired attention, once auditory and/or visual areas of weakness have been strengthened, many of the disruptive behavioral symptoms diminish (Ghaziri et al., 2013; Zhonggui, Shuhua, \& Haiqing, 2005). This study specifically identified that artifactcorrected neurofeedback, which works by filtering out the contamination that continually results from naturally occurring EMG artifacts such as eye blinks, eye movements, and facial activity significantly improved both auditory and visual attention in impaired children.

As a group, these children initially presented as significantly impaired. After 40 half-hour treatment sessions, both their auditory and visual attention abilities improved and most IVA-2 scale score means were found to fall within the "normal" range (i.e., defined as a standard score of 77 or higher, 1.5 standard deviations; Sandford \& Sandford, 2014) and all scales had effect sizes in the medium to large range demonstrating the clinical efficacy of this neurofeedback therapy. A standard score change of 8 points or more is clinically significant. With the additional 20 sessions, children gained $8+$ points, and in some cases, a full $S D$ of $15+$ points. All scale score means improved from baseline to 20 sessions ranging from a 12-point to 24-point increase, except for SAAQ, which showed a 7-point increase.

The results of this archival study reveal that impaired children $(N=51)$ in this study needed 40 sessions to reach a normalized score. Improvements were noted across all global and standard scales, improvements were comprehensive and included both auditory and visual modalities. The improvements included response control (i.e., vigilance, consistency and stamina) in addition to both general attention (i.e., accuracy, consistency and speed) and sustained attention.

There were differences based on medium vs. large size effects for SVAQ versus SAAQ and ARCQ versus VRCQ. The SVAQ standard scales showed large effect size improvements (baseline to 40 sessions) and the SAAQ showed medium effect size improvements (baseline to 40 sessions). ARCQ showed large effect size improvements from the severely impaired range to only being slightly impaired (baseline to 40 sessions) and the VRCQ showed medium effect size improvements (baseline to 40 sessions). In respect to clinical improvement, greater changes were found on average for the visual attention scales (VAQ and SVAQ) in comparison to the auditory attention scales (AAQ and SAAQ) with these visual scale scores improving by $.5 S D$ more than the auditory attention scales.

While this study utilized archival data and there was no control group to evaluate for possible test practice effects, the IVA-2 is an objective measure of attention which controls for practice effects in both its simplistic design (i.e., the test rule is to click if you see or hear the number one) and in its pretest instruction phase, which includes specific opportunities for individuals to practice the test before taking it. The reliability study in the test manual found that, on retesting, subjects did not significantly change by more than 3 to 4 points in either direction (Sandford \& Sandford, 2014). Thus, any group increases in IVA-2 quotient scores greater than 3 to 4 points can be validly interpreted as a result of an active treatment and not due to practice effects. In this study, it was found that 40 half-hour neurofeedback sessions led specifically to the significant enhancement of auditory and visual attention as evidenced by the greater effect sizes observed and the significant increase in both auditory and visual attention scales from baseline to 20 sessions and from 20 to 40 sessions.

Thus, the hypothesis of this study that neurofeedback would significantly improve both auditory and visual attention was confirmed, and effect sizes were large for the enhancement on the three comprehensive IVA-2 global measures of general attention, sustained attention and response control (FRCQ, FAQ, and SFAQ, respectively). The findings of this archival study support that neurofeedback offers the potential as an alternative, nonpharmacological treatment approach that is clinically efficacious without any significant side effects.

Lubar (1995) found that the benefits of neurofeedback can potentially be long lasting. In a 10-year follow-up study, Lubar reported that about $80 \%$ of clients treated with neurofeedback substantially improved their symptoms of ADD and $A D H D$, and that the changes were maintained. Cannon and Lubar (2011) later reported that neurofeedback training may generate a global integration effect that progresses on a continuum yielding ongoing improvements in the areas of working memory, higher order executive functioning, affective processing, attention, and cognition. In 
general, neurofeedback is becoming more widely accepted by many health care professionals and warrants institutional and governmental support for new research specifically with children who have ADHD symptomatology based on the results of this study and numerous others.

This research finding further substantiates the value and benefit of utilizing this new artifact corrected type of neurofeedback in the treatment of children with symptoms of ADHD and warrants further research as a neurofeedback intervention. In this study, initially children $(N=51)$ were found to be experiencing significant levels of attention impairment. After receiving neurofeedback treatment without any supportive counseling or coaching, all of them improved across the nine global and standard score measures of auditory and visual processing. Thus, the benefits of artifact corrected type neurofeedback demonstrated potential to help children improve their attentional functioning, which is consistent with the findings of La Marca et al. (2018) and consistent with the findings of improved attentional functioning of McReynolds et al. (2017).

In interpreting the results of this study, certain limitations were considered. A primary drawback was its archival nature. Follow-up evaluations at 6 months and 1 year to determine the long-term effects of neurofeedback treatment are also components recommended for consideration for future studies in this field.

While this archival research was not designed to evaluate learning effects, the evaluation and demonstration of individuals' learned control of brainwave activity is an important issue which needs to be addressed in future research. Thus, research specifically designed to measure learning effects respective to the targeted EEG frequencies trained is recommended. However, in order to evaluate learning effects this type of study would require that all participants in the study receive training that used the same standardized treatment protocol for each person. Any clinical modifications to meet a person's specific needs would not be permitted.

Based on 8 years of work with children using EEG biofeedback, children in our clinic have reported they are "able to pay attention even when they don't want to..." and that they are able to "choose whether to focus on what their friends are saying in the classroom or to listen to the teacher." Children in our clinic have gone from earning poor grades to passing grades, some excelling to the level of being on the honor roll for the first time in their academic lives. Based on child and parent self-report, the resulting enhanced attentional auditory and visual processing has led to improvements in academic work, decreased behavioral interventions, and improved family dynamics.

\section{Future Directions}

School systems use levels of interventions to support school-aged children's behavior, social, emotional, and academic readiness. Traditional forms of schoolbased interventions consist of approaches (i.e., Positive Behavioral Interventions and Supports; PBIS) to promote and improve social, emotional, and academic outcomes for all students. Behavioral interventions (i.e., Applied Behavioral Analysis; ABA) implement classical forms of conditioning to alter behaviors or introduce an alternative appropriate behavior.

Additional forms of support targeting specific areas of student social and emotional development are provided by mental health providers within the school setting through individual or group therapy. The goals of these interventions are to enhance the skills and competencies of school-aged children to be successful in school. Each of these interventions involves using visual or auditory instructions designed to enhance learning. The consistent limitation of each of these traditional school-based interventions is that children must be able to process the intervention information. As discussed earlier, if a child is unable to process auditory or visual information even the best planned interventions may fail.

In the future, coupling neurofeedback interventions with school-based support may provide a more effective and individualized form of intervention. Furthermore, neurofeedback intervention in schools may provide educators with additional tools and knowledge to individualize student support. La Marca and O'Connor (2016) found that by using neurofeedback children were able to improve their reading comprehension and demonstrated more focused attention in the classroom.

Using the IVA-2 as an initial assessment tool will provide school interventionists with specific information on the student's auditory and visual processing strengths and weaknesses. With more specific information gleaned from the IVA-2, interventions can be developed targeting specific areas of weakness and used to modify the learning environment while the student is participating in a neurofeedback training program. In addition, the 
neurofeedback assessment and treatment process would serve as an intervention providing additional documentation in determining whether or not there is a need for a special education assessment.

Development of a pilot project in the school setting is necessary to support students by identifying auditory and visual processing difficulties. Offering individualized neurofeedback training in the school setting would generate useful information regarding alternative interventions that may reduce referrals to Special Education. In other words, if neurofeedback and the IVA-2 assessment can identify children who have auditory and visual processing difficulties and effectively reduce these impairments, school districts may find a reduction in the need for Special Education services for this group of children. A reduction in the use of Special Education services would benefit the school district as well as benefiting the children if they are not in actual need of these specialized services.

Neurofeedback provides the opportunity for students to retrain their self-regulation abilities associated with social-emotional wellness (Huang-Storms, Bodenhamer-Davis, Davis, \& Dunn, 2007), a process that is not typically accomplished with pharmaceutical interventions. Current estimates of annual out-ofpocket costs associated with traditional ADHD treatment approaches (i.e., medication and therapist visits) averaged \$2,125 per child in 2012 (Doshi et al., 2012), which is approximately equal to 20 hours of neurofeedback training. When coupled with the average annual cost to society of $\$ 5,007$ per child (Robb et al., 2011), the financial cost to schools, to families, and to society suggest that alternative treatments for ADHD are necessary to help reduce the large financial impact of ADHD (Doshi et al., 2012). The use of neurofeedback is a viable alternative that addresses the underlying associated problems of auditory and visual processing at the core of many of the symptoms of ADHD. Given the ongoing annual costs of traditional approaches to ADHD, neurofeedback becomes a viable and costreducing nonpharmaceutical alternative; even more so given the potential for long-term, ongoing benefits gained following neurofeedback treatment (Cannon \& Lubar, 2011; Lubar, 1995).

The enhancement of social-emotional well-being has the capacity to improve a student's academic performance (Durlak, Weissberg, Dymnicki, Taylor, \& Schellinger, 2011; La Marca \& O'Connor, 2016). Additionally, by including neurofeedback as a form of support for school-aged children educators would have access to an alternative intervention. As a nonpharmacological intervention, neurofeedback provides a mechanism that teaches children how to function better by training their brain. Therefore, neurofeedback as a form of intervention in the school systems should be considered in future research directions.

\section{Conclusion}

The results of this study supported the hypothesis that neurofeedback would significantly improve both auditory and visual attention of children with symptoms of ADHD. The children's improvement in their auditory and visual attention scores revealed they achieved clinically significant improvements after 40 half-hour treatment sessions. Artifact corrected neurofeedback proved to be a clinically efficacious intervention that helps normalize the significant attentional impairments symptomatic of ADHD in children ages 6 to 17 .

\section{References}

American Academy of Audiology. (2010). Clinical practice guidelines. Diagnosis, treatment and management of children and adults with central auditory processing disorder. Retrieved May 2016 from https://audiologyweb.s3.amazonaws.com/migrated/CAPD Guidelines 82010.pdf_539952af956c79.73897613.pdf

American Psychiatric Association. (2013). Diagnostic and Statistical Manual of Mental Disorders (5th ed.). Washington, DC: Author. Retrieved from http://dx.doi.org/10.1176 lappi.books. 9780890425596

Behavioural Neurotherapy Clinic. (n.d.). Central Auditory Processing Disorder (CAPD). Retrieved May 1, 2016, from http://www.adhd.com.au/CAPD.htm

Brazier, Y. (2015, November 25). "ADHD medication: Is it a good idea?" Medical News Today. Retrieved May 2016 from https://www.medicalnewstoday.com/articles/303090.php

Breslau, J., Miller, E., Chung, W.-J. J., \& Schweitzer, J. B. (2011). Childhood and adolescent onset psychiatric disorders, substance use, and failure to graduate high school on time. Journal of Psychiatry Research, 45(3), 295-301. http://dx.doi.org/10.1016/j.jpsychires.2010.06.014

Cannon, R., \& Lubar, J. (2011). Long-term effects of neurofeedback training in anterior cingulate cortex: A short follow-up report, Journal of Neurotherapy, 15(2), 130-150. http://dx.doi.org/10.1080/10874208.2011.570688

Chermak, G. D., \& Musiek, F. E. (1997). Central auditory processing disorders: New perspectives. San Diego, CA: Singular Publishing Group, Inc.

Chronis-Tuscano, A., Molina, B. S. G., Pelham, W. E., Applegate, B., Dahlke, A., Overmeyer, M., \& Lahey, B. B. (2010). Very early predictors of adolescent depression and suicide attempts in children with attention-deficit/hyperactivity disorder. Archives in General Psychiatry, 67(10), 1044-1051. http://dx.doi.org/10.1001/archgenpsychiatry.2010.127

Daley, D., van der Oord, S., Ferrin, M., Danckaerts, M., Doepfner, M., Cortese, S., \& Sonuga-Barke, E. J. S. (2014). Behavioral interventions in attention-deficit/hyperactivity disorder: A metaanalysis of randomized controlled trials across multiple outcome domains. Journal of the American Academy of Child 
\& Adolescent Psychiatry, 53(8), 835-847.e5. http://dx.doi.org /10.1016/j.jaac.2014.05.013

Doshi, J. A., Hodgkins, P., Kahle, J., Sikirica, V., Cangelosi, M. J., Setyawan, J., ... Neumann, P. J. (2012). Economic impact of childhood and adult attention-deficit/hyperactivity disorder in the United States. Journal of the American Academy of Child \& Adolescent Psychiatry, 51(10), 990-1002.e2. http://dx.doi.org/10.1016/j.jaac.2012.07.008

Dunlop, A. J., \& Newman, L. K. (2016). ADHD and psychostimulants-Overdiagnosis and overprescription. The Medical Journal of Australia, 204(4), 139. http://dx.doi.org $/ 10.5694 / \mathrm{mja} 15.01387$

Durlak, J. A., Weissberg, R. P., Dymnicki, A. B., Taylor, R. D., \& Schellinger, K. B. (2011). The impact of enhancing students' social and emotional learning: A meta-analysis of schoolbased universal interventions. Child Development, 82(1), 405432. http://dx.doi.org/10.1111/j.1467-8624.2010.01564.x

Ellis, M. (2016, March 3). "ADHD medication and low bone density: Are kids at risk?" Medical News Today. Retrieved May 30, 2016, from https://www.medicalnewstoday.com /articles/307389.php

Epstein, V. (2015, June 17). "Visual processing disorder: Is this what your child has?" Kars4Kids Smarter Parenting. Retrieved May 2016 from http://www.kars4kids.org/blog /visualprocessing-disorder-is-this-what-your-child-has

Evans, S. W., Owens, J. S., \& Bunford, N. (2014). Evidence-based psychosocial treatments for children and adolescents with attention-deficit/hyperactivity disorder. Journal of Clinical Child \& Adolescent Psychology, 43(4), 527-551. http://dx.doi.org/10.1080/15374416.2013.850700

Fabiano, G. A., Pelham, W. E., Coles, E. K., Gnagy, E. M., ChronisTuscano, A., \& O'Connor, B. C. (2009). A meta-analysis of behavioral treatments for attention-deficit/hyperactivity disorder. Clinical Psychology Review, 29(2), 129-140. http://dx.doi.org/10.1016/j.cpr.2008.11.001

Farrar, R., Call, M., \& Maples, W. C. (2001). A comparison of the visual symptoms between ADD/ADHD and normal children. Optometry, 72(7), 441-451.

Ghaziri, J., Tucholka, A., Larue, V., Blanchette-Sylvestre, M., Reyburn, G., Gilbert, G., ... Beauregard, M. (2013). Neurofeedback training induces changes in white and gray matter. Clinical EEG and Neuroscience, 44(4), 265-272. http://dx.doi.org/10.1177/1550059413476031

Gleason, M. M. (2013). Finding the tools for effective early intervention for preschool attention-deficit/hyperactivity disorder. Journal of the American Academy of Child \& Adolescent Psychiatry, 52(3), 228-230. http://dx.doi.org /10.1016/j.jaac.2012.12.008

Grohol, J. M., (2013). Is ADHD overdiagnosed? Yes \& no. Retrieved May 2016 from http://psychcentral.com/blog /archives/2013/11/21/is-adhd-overdiagnosed-yes-no/

Gyldenkærne, P., Dillon, H., Sharma, M., \& Purdy, S. C. (2014). Attend to this: The relationship between auditory processing disorders and attention deficits. Journal of the American Academy of Audiology, 25(7), 676-687. http://dx.doi.org /10.3766/jaaa.25.7.6

Hagen, H., Moore, K., Wickham, G., \& Maples, W. C. (2008). Effect on the EYEPORT system of visual function in ADHD children: A pilot study. Journal of Behavioral Optometry, 19(2), 37-41.

Hammond, D.C. (2011). What is neurofeedback: an update. Journal of Neurotherapy, 15(4), 305-336, http://dx.doi.org /10.1080/10874208.2011.62309

Hinshaw, S. P., \& Ellison, K. (2016). ADHD: What everyone needs to know. New York, NY: Oxford University Press.

Hinshaw, S. P., Owens, E. B., Zalecki, C., Huggins, S. P., Montenegro-Nevado, A. J., Schrodek, E., \& Swanson, E. N. (2012). Prospective follow-up of girls with attentiondeficit/hyperactivity disorder into early adulthood: Continuing impairment includes elevated risk for suicide attempts and self- injury. Journal of Consulting and Clinical Psychology, 80(6), 1041-1051. http://dx.doi.org/10.1037/a0029451

Hinshaw, S. P., \& Scheffler, R. M. (2014). The ADHD explosion: Myths, medication, money, and today's push for performance. New York, NY: Oxford University Press.

Huang-Storms, L., Bodenhamer-Davis, E., Davis, R., \& Dunn, J. (2007). QEEG-guided neurofeedback for children with histories of abuse and neglect: Neurodevelopmental rationale and pilot study. Journal of Neurotherapy, 10(4), 3-16. http://dx.doi.org/10.1300/J184v10n04_02

International Statistical Classification of Diseases and Related Health Problems 10th Revision (ICD-10) Diagnosis Codes F90: Attention-deficit hyperactivity disorders. Retrieved April 2016 from https://www.icd10data.com/ICD10CM/Codes/F01 F99/F90-F98/F90-

La Marca, J. P., Cruz, D., Fandino, J., Cacciaguerra, F. R., Fresco, J. J., \& Guerra, A. T. (2018). Journal of Neural Transmission, 125(7), 1087-1097. http://dx.doi.org/10.1007 /s00702-0181877-1

La Marca, J. P., \& O'Connor, R. E. (2016). Neurofeedback as an Intervention to improve reading achievement in students with attention-deficit/hyperactivity disorder, inattentive subtype. NeuroRegulation, 3(2), 55-77. http://dx.doi.org/10.15540 /nr.3.2.55

Lee, S. S., Lahey, B. B., Owens, E. B., \& Hinshaw, S. P. (2008) Few preschool boys and girls with ADHD are well-adjusted during adolescence. Journal of Abnormal Child Psychology, 36(3), 373-383. http://dx.doi.org/10.1007/s10802-007-9184-6

Lubar, J. F. (1995). Neurofeedback for the management of attention-deficit/hyperactivity disorders. In M. S. Schwartz (Ed.), Biofeedback: A practitioner's guide (pp. 493-522). New York, NY: Guilford Press.

Maddux, C. D. (2010). [Review of the IVA+Plus: Integrated Visual and Auditory Continuous Performance Test]. In R. A. Spies, J. F. Carlson, \& K. F. Geisinger (Eds.), The eighteenth mental measurements yearbook (pp. 434-437). Lincoln, NE: Buros Institute of Mental Measurements.

McCallum, W. C. (2015). Attention. Encyclopædia Britannica. Encyclopædia Britannica, Inc. Retrieved from http://www.britannica.com/science/attention/Theneurophysiology-of-attention

McReynolds, C. J., Bell, J., \& Lincourt, T. M. (2017) Neurofeedback: A noninvasive treatment for symptoms of posttraumatic stress disorder in veterans. NeuroRegulation, 4(3-4), 114-124. http://dx.doi.org/10.15540/nr.4.3-4.114

Moore, D. R., Ferguson, M. A., Edmondson-Jones, A. M., Ratib, S., \& Riley, A. (2010). Nature of auditory processing disorder in children. Pediatrics, 126(2), e382-e390. http://dx.doi.org/10.1542 /peds.2009-2826

MTA Cooperative Group. (2004). National Institute of Mental Health multimodal treatment study of ADHD follow-up: Changes in effectiveness and growth after the end of treatment. Pediatrics, 113(4), 762-769.

New Brunswick Department of Education. (1999). Resource for the identification and teaching of students with specific learning disability. Retrieved from https://www2.gnb.ca /content/dam/gnb/Departments/ed/pdf/K12/ResourceForldenti ficationTeachingStudentsSpecificLearningDisability.pdf

Norman, D. A. (1982). Memory and attention: An introduction to human information processing (2nd ed.). New York, NY: Wiley.

Owens, E. B., Hinshaw, S. P., Lee, S. S. \& Lahey, B. B. (2009). Few girls with childhood attention-deficit/hyperactivity disorder show positive adjustment during adolescence. Journal of Clinical Child \& Adolescent Psychology, 38(1), 132-143. http://dx.doi.org/10.1080/15374410802575313

Pingault, J.-B., Tremblay, R. E., Vitaro, F., Carbonneau, R., Genolini, C., Falissard, B., \& Côté, S. M. (2011). Childhood trajectories of inattention and hyperactivity and prediction of educational attainment in early adulthood: A 16-year 
longitudinal population-based study. The American Journal of Psychiatry, 168(11), 1164-1170. http://dx.doi.org/10.1176 lappi.ajp.2011.10121732

Poulton, A. S., Melzer, E., Tait, P. ., Garnett, S. P., Cowell, C. T., Baur, L. A., \& Clarke, S. (2013). Growth and pubertal development in adolescent boys on stimulant medication for attention deficit hyperactivity disorder. The Medical Journal of Australia, 198(1), 29-32. http://dx.doi.org/10.5694 Imja12.10931

Prasad, V., Brogan, E., Mulvaney, C., Grainge, M., Stanton, W., \& Sayal, K. (2013). How effective are drug treatments for children with $\mathrm{ADHD}$ at improving on-task behaviour and academic achievement in the school classroom? A systematic review and meta-analysis. European Child \& Adolescent Psychiatry, 22(4), 203-216. http://dx.doi.org /10.1007/s00787-012-0346-x

Riddle, M. A., Yershova, K., Lazzaretto, D., Paykina, N., Yenokyan, G., Greenhill, L., ... Posner, K. (2013). The preschool attentiondeficit/hyperactivity disorder treatment study (PATS) 6-year follow-up. Journal of the American Academy of Child \& Adolescent Psychiatry, 52(3), 264-278.e2. http://dx.doi.org/10.1016/j.jaac.2012.12.007

Robb, J. A., Sibley, M. H., Pelham, W. E., Foster, E. M., Molina, B. S. G., Gnagy, E. M., \& Kuriyan, A. B. (2011). The estimated annual cost of ADHD to the U.S. education system. School Mental Health, 3(3), 169-177. http://dx.doi.org/10.1007 /s12310-011-9057-6

Sandford, J. A., \& Sandford, S. E. (2014). IVA-2: Integrated Visual and Auditory Continuous Performance Test Manual. North Chesterfield, VA: Brain Train, Inc.

Saul, R. (2014). ADHD Does Not Exist. New York, NY: HarperCollins Publishers.

Sharma, M., Purdy, S. C., \& Kelly, A. S. (2009). Comorbidity of auditory processing, language, and reading disorders. Journal of Speech, Language, and Hearing Research, 52, 706-722. http://dx.doi.org/10.1044/1092-4388(2008/07-0226)

Sonuga-Barke, E. J. S., Brandeis, D., Cortese, S., Daley, D., Ferrin M., Holtmann, M., ... European ADHD Guidelines Group. (2013). Nonpharmacological interventions for ADHD: Systematic review and meta-analyses of randomized controlled trials of dietary and psychological treatments. The American Journal of Psychiatry, 170(3), 275-289. http://dx.doi.org/10.1176/appi.ajp.2012.12070991
Steiner, N. J., Sheldrick, R. C., Gotthelf, D., \& Perrin, E. C. (2011). Computer-based attention training in the schools for children with attention deficit/hyperactivity disorder: A preliminary trial. Clinical Pediatrics, 50(7), 615-622. http://dx.doi.org/10.1177 10009922810397887

Swanson, J. M., Arnold, L. E., Molina, B. S. G., Sibley, M. H., Hechtman, L. T., Hinshaw, S. P., ... for the MTA Cooperative Group. (2017). Young adult outcomes in the follow-up of the multimodal treatment study of attention-deficit/hyperactivity disorder: Symptom persistence, source discrepancy, and height suppression. The Journal of Child Psychology and Psychiatry, 58(6), 663-678. http://dx.doi.org/10.1111 ljcpp.12684

Swanson, J. M., \& Volkow, N. D. (2009). Psychopharmacology: Concepts and opinions about the use of stimulant medications. The Journal of Child Psychology and Psychiatry, 50(1-2), 180193. http://dx.doi.org/10.1111/j.1469-7610.2008.02062.x

Swingle, P. G. (2015). When the ADHD diagnosis is wrong: Understanding other factors that affect attention in children. Santa Barbara, CA: Praeger.

Tomlin, D., Dillon, H., Sharma, M., \& Rance, G. (2015). The impact of auditory processing and cognitive abilities in children. Ear and Hearing, 36(5), 527-542. http://dx.doi.org/ 10.1097/AUD.0000000000000172

Visser, S. N., Zablotsky, B., Holbrook, J. R., Danielson, M. L., \& Bitsko, R. H. (2015). Diagnostic experiences of children with attention-deficit/hyperactivity disorder. National Health Statistics Reports; 81, 1-7. Hyattsville, MD: National Center for Health Statistics.

Woliver, R., \& Ibrahim, M. (2012). Auditory processing disorder: The hidden disability. Long Island Press. Retrieved May 2016 from http://newideas.net/auditory-processing-disorder

Zhonggui, X., Shuhua, S., \& Haiqing, X. (2005). A controlled study of the effectiveness of EEG biofeedback training on children with attention deficit hyperactivity disorder. Journal of Huazhong University of Science and Technology, 25(3), 368370. http://dx.doi.org/10.1007/BF02828171

Received: November 14, 2018

Accepted: November 20, 2018

Published: December 7, 2018 


\section{Appendix}

Description of IVA-2 Global and Standard Composite Scores

The IVA-2 provides nine global composite quotient scores to help gain an in-depth understanding of the variety of ways ADHD-type problems may manifest (Sandford \& Sandford, 2014).

\begin{tabular}{|c|c|}
\hline IVA-2 Measures & Description of Measures \\
\hline $\begin{array}{l}\text { AAQ } \\
\text { (Auditory Attention Quotient) }\end{array}$ & Based on equal measures of auditory Vigilance, Focus, and Speed \\
\hline $\begin{array}{l}\text { ARCQ } \\
\text { (Auditory Response Control Quotient) }\end{array}$ & Derived from auditory Prudence, Consistency, and Stamina scales \\
\hline $\begin{array}{l}\text { FAQ } \\
\text { (Full Scale Attention Quotient) }\end{array}$ & $\begin{array}{l}\text { Based on six primary visual and auditory scales each based on } \\
\text { equal measures of visual and auditory Vigilance, Focus, and Speed }\end{array}$ \\
\hline $\begin{array}{l}\text { FRCQ } \\
\text { (Full Scale Response Control Quotient) }\end{array}$ & $\begin{array}{l}\text { Based on six primary visual and auditory scales each and equal } \\
\text { weights (not an average) of ARCQ and VRCQ scales }\end{array}$ \\
\hline $\begin{array}{l}\text { SAAQ } \\
\text { (Sustained Auditory Attention Quotient) }\end{array}$ & $\begin{array}{l}\text { Provides a global measure of a person's ability to respond to } \\
\text { auditory stimuli under low demand conditions }\end{array}$ \\
\hline $\begin{array}{l}\text { SFAQ } \\
\text { (Sustained Full Scale Attention Quotient) }\end{array}$ & Combined global measure of the SAAQ and SVAQ global scales \\
\hline $\begin{array}{l}\text { SVAQ } \\
\text { (Sustained Visual Attention Quotient) }\end{array}$ & $\begin{array}{l}\text { Provides a global measure of a person's ability to respond to visual } \\
\text { stimuli under low demand conditions }\end{array}$ \\
\hline $\begin{array}{l}\text { VAQ } \\
\text { (Visual Attention Quotient) }\end{array}$ & Based on equal measures of visual Vigilance, Focus, and Speed \\
\hline $\begin{array}{l}\text { VRCQ } \\
\text { (Visual Response Control Quotient) }\end{array}$ & Derived from visual Prudence, Consistency, and Stamina scales \\
\hline
\end{tabular}

\begin{tabular}{|c|c|}
\hline IVA-2 Scales & Description of Scales \\
\hline \multicolumn{2}{|c|}{ Attention Primary Scales } \\
\hline Vigilance & $\begin{array}{l}\text { Measure of inattention as evidenced by two different types of errors } \\
\text { of omission }\end{array}$ \\
\hline Focus & $\begin{array}{l}\text { Reflects the total variability of mental processing speed for all } \\
\text { correct responses }\end{array}$ \\
\hline Speed & $\begin{array}{l}\text { Reflects the average reaction time for all correct responses } \\
\text { throughout the test and helps to identify attention-processing } \\
\text { problems related to slow discriminatory mental processing }\end{array}$ \\
\hline \multicolumn{2}{|c|}{ Response Control Primary Scales } \\
\hline Prudence & $\begin{array}{l}\text { Measure of impulsivity and response inhibition as evidenced by } \\
\text { three different types of errors of commission }\end{array}$ \\
\hline Consistency & $\begin{array}{l}\text { Measures the general reliability and variability of response times and } \\
\text { is used to help measure the ability to stay on task }\end{array}$ \\
\hline Stamina & $\begin{array}{l}\text { Compares the mean reaction times of correct responses during the } \\
\text { first } 100 \text { trials to the last } 100 \text { trials; this score is used to identify } \\
\text { problems related to sustaining attention and effort over time }\end{array}$ \\
\hline
\end{tabular}

